\title{
USO DE COPRÓLITOS DE MINHOCA NA PRODUÇÃO DE MUDAS DE MAMOEIRO ${ }^{1}$
}

\author{
JORGE FERREIRA KUSDRA², DIRCEU FÉLIX MOREIRA ${ }^{3}$ SONAIRA SOUZADA SILVA ${ }^{4}$, \\ SEBASTIÃO ELVIRO DE ARAÚJO NETO ${ }^{5}$, RODRIGO GUEDES DA SILVA $^{6}$
}

RESUMO - O objetivo desta pesquisa foi avaliar o efeito de substratos preparados com diferentes proporções de solo e de coprólitos de minhoca na produção de mudas de mamoeiro. Foram realizados dois experimentos no viveiro de produção de mudas da Universidade Federal do Acre - UFAC, ambos obedecendo ao delineamento inteiramente casualizado, com 11 tratamentos e 10 repetições. Os tratamentos foram definidos pela mistura de diferentes concentrações $(0 ; 10 ; 20 ; 30 ; 40 ; 50 ; 60 ; 70 ; 80 ; 90$ e 100\%) de coprólitos de minhoca (Chibui bari) e de solo, sendo este distrófico $(\mathrm{V}=29 \%)$ no experimento 1 e eutrófico $(\mathrm{V}=80 \%)$ no experimento 2 . Após 60 dias da semeadura, avaliaram-se altura das plantas e as massas da matéria seca da parte aérea, da raiz e total. Verificou-se que a adição de doses crescentes de coprólitos na composição do substrato resultou em aumento do crescimento das plantas no experimento 1 e em redução no experimento 2. Os resultados dos experimentos indicam que o uso de coprólitos de minhoca em substratos preparados com solo somente contribui para o aumento do crescimento de mudas de mamão formosa se a condição química desse material orgânico for mais adequada que a do solo em atender às necessidades nutricionais das plantas. Os resultados do experimento com solo distrófico indicam a possibilidade de uso dos coprólitos na produção tradicional de mudas de mamoeiro, especialmente em situações onde o solo apresenta restrições quanto à condição química.

Termos para indexação: Carica papaya L. Chibui bari. Substratos. Adubação orgânica.

\section{USE OF EARTHWORM CASTING IN THE PRODUCTION OF PAPAYA SEEDLINGS}

ABSTRACT - The purpose of this investigation was to evaluate the effect of substrates prepared with different proportion of soil and earthworm casting in the seedlings production of papaya. Two experiments were carried out in nursery of seedlings production of Federal University of the Acre - UFAC, both complying with completely randomized design with eleven treatments and ten replications. The treatments represent the mixture of different concentrations $(0,10,20,30,40,50,60,70,80,90$ e 100\%) of earthworm (Chibui bari) casting and soil, being dystrophic $(\mathrm{V}=29 \%)$ in the experiment 1 and eutrophic $(\mathrm{V}=80 \%)$ in the experiment 2 . After 60 days of the planting the seeds was evaluated height of the plant and dry weight matter masses of shoot, root and total. It was verified that the addition of increasing doses of earthworm casting in the composition of the substrate resulted in increase of the growth of the plants in experiment 1 and reduction in experiment 2. The results of the experiments indicate that the use of earthworm casting in substrate prepared with soil only contributes for the increase of the growth seedlings of formosa papaya if the chemical condition of this organic material more will be appropriate than of the soil in taking care of the nutrition necessities of the plants. The results of the experiment with dystrophic soil indicate the possibility of use of the earthworm casting in the traditional production of papaya, especially in situations where the soil presents restrictions how much to the chemical condition.

Index terms: Carica papaya L. Chibui bari. Substrate. Organic fertilization.

\section{INTRODUÇÃO}

O mamoeiro é uma fruteira cultivada praticamente em todo o Brasil, permitindo ao País ser seu maior produtor mundial (Agrianual, 2005). Porém, o êxito de plantios comerciais depende de vários fatores, destacando-se o uso de mudas de boa qualidade. Portanto, para a obtenção de altas produtividades, torna-se fundamental que, na fase de viveiro, sejam utilizados substratos com características que favoreçam a germinação das sementes, o desenvolvimento radicular e o crescimento inicial das plantas (Ramos et al., 2002). Entretanto, além da necessidade de os substratos apresentarem propriedades químicas e físico-hídricas adequadas, de forma a melhorar a relação água/ar e a disponibilidade de nutrientes (Fernandes \& Corá, 2000), estes devem também estar livres de fitopatógenos e sementes de plantas indesejáveis e serem compostos por materiais de baixo custo e fácil aquisição (Fachinello et al., 2005).

A incorporação de compostos orgânicos ao substrato pode contribuir para a melhoria de suas características físicas e químicas, proporcionando melhores condições ao crescimento adequado das mudas. No caso do vermicomposto ("húmus de minhoca"), este permite obter substratos mais densos, porém com maior quantidade de macroporos (Fernandes \& Corá, 2000). Embora existam muitos trabalhos destinados a avaliar a eficiência de uso

${ }^{1}$ (Trabalho 155-07). Recebido em: 19-06-2007. Aceito para publicação em:14-12-2007.

${ }^{2}$ Eng.Agr. Dr. Agronomia. Prof. Adjunto. Departamento de Ciências Agrárias. Universidade Federal do Acre (UFAC). BR 364, Km 04 - Rio Branco, AC, 69.915-900. E-mail: j.f.k@terra.com.br.

${ }^{3}$ Eng.Agr., Egresso do Curso de Eng. Agronômica da UFAC. E-mail: dirceufelix@hotmail.com.

${ }^{4}$ Estudante do Curso de Eng. Agronômica da UFAC. E-mail: sonairasouza@yahoo.com.br.

${ }^{5}$ Eng.Agr. Dr. Fitotecnia. Prof. Adjunto. Departamento de Ciências Agrárias. UFAC. E-mail: selviro2000@yahoo.com.br.

${ }^{6}$ Eng.Agr. Mestrando em Agronomia - Produção Vegetal pela UFAC. E-mail: rodrigo78br@yahoo.com.br

Rev. Bras. Frutic., Jaboticabal - SP, v. 30, n. 2, p. 492-497, Junho 2008 
de vermicompostos na composição de substratos para produção de mudas de várias espécies de plantas (Bakker, 1994; Blank et al., 2003; Cabrera, 2004; Castro et al., 2003; Diniz et al., 2001; Martins et al., 2001; Mendonça et al., 2003; Menezes Júnior \& Fernandes, 1998; Silveira et al., 2002; Souza et al., 2003; Vidal et al., 2006), há deficiência de pesquisas visando à utilização direta dos coprólitos de minhocas com essa finalidade.

Em estudos realizados no Parque Zoobotânico da Universidade Federal do Acre, verificou-se que minhocas da espécie Chibui bari (Glossoscolecidae, Oligochaeta) liberam dejetos (coprólitos) na superfície do solo que formam montículos de até $30 \mathrm{~cm}$ de altura, chegando a produzir até 88,3 tha/ano (Guerra, 1988). Essa situação atende à recomendação de utilização na composição dos substratos de materiais de baixo custo, fácil acesso e grande disponibilidade (Silveira, 2002; Souza \& Resende, 2003).

O presente trabalho teve o objetivo de avaliar a influência de substratos preparados com mistura de solo e coprólitos de minhoca no crescimento de mudas de mamoeiro do grupo formosa.

\section{MATERIAL E MÉTODOS}

Dois experimentos foram conduzidos no viveiro de produção de mudas da Universidade Federal do Acre. Ambos foram instalados obedecendo ao delineamento inteiramente casualizado, com 11 tratamentos obtidos a partir da mistura volumétrica de concentrações de 0 a $100 \%$ de coprólito de minhoca (Chibui bari) e solo, sendo este distrófico ( $\mathrm{V}=29 \%)$ no Experimento 1 e eutrófico $(\mathrm{V}=80 \%$ ) no Experimento 2 (Tabela 1).

Cada tratamento foi repetido 10 vezes, tendo como unidade experimental sacos plásticos de polietileno preto com dimensões de 17,5 $\mathrm{cm}$ de comprimento por $7 \mathrm{~cm}$ de diâmetro.

A semeadura foi realizada diretamente nos sacos, colocando-se três sementes na profundidade de $1 \mathrm{~cm}$. O desbaste foi feito aos 20 dias após a semeadura, sendo mantida apenas uma planta em cada saco. Os tratos culturais limitaram-se à irrigação e ao controle de plantas daninhas.

Os coprólitos foram coletados da superfície do solo do Câmpus da Universidade Federal do Acre em área sob floresta nativa secundária. Posteriormente, foram misturados e peneirados para promover sua homogeneização. As amostras de solo utilizadas nos experimentos também foram peneiradas antes de se proceder a sua mistura aos coprólitos para a constituição volumétrica dos substratos conforme definidos pelos tratamentos. Para a caracterização físico-química dos substratos, realizaram-se as análises de fertilidade (Tabelas 2 e 3) e físicas (Tabela 4) referentes a ambos os experimentos.

A avaliação dos experimentos foi realizada aos 60 dias após a semeadura. Foram consideradas as seguintes variáveis indicadoras de crescimento das plantas: altura, massa da matéria seca da parte aérea, massa da matéria seca da raiz e massa da matéria seca total da planta. A altura das mudas foi medida no próprio viveiro. Para a obtenção das massas secas, as plantas foram colocadas e mantidas em estufa a $60^{\circ} \mathrm{C}$ até alcançar massa constante.
Os resultados das variáveis avaliadas em ambos os experimentos foram submetidos à análise de regressão, sendo consideradas as equações de maior grau significativo $(p<0,05)$.

\section{RESULTADOS E DISCUSSÃO}

No experimento utilizando solo distrófico, observou-se diferença significativa entre os tratamentos para a altura da planta (Figura 1), massa da matéria seca da parte aérea, da raiz e total da planta ( Figura 2). Verificou-se que a adição de coprólitos a um solo ácido, pobre em nutrientes, com alta saturação de alumínio e com baixos níveis de matéria orgânica pode proporcionar melhor condicionamento químico do substrato (Tabela 2) e, dessa forma, contribuir para o aumento do crescimento das mudas. Além disso, os resultados indicam que a resposta positiva no crescimento das plantas é proporcional ao aumento de coprólitos e à redução do solo na composição do substrato, observando-se um comportamento linear para a altura das plantas e quadrático para as massas de matéria seca da parte aérea, da raiz e total da planta.

$\mathrm{O}$ efeito benéfico da adição de doses crescentes de coprólitos na melhoria da condição química do substrato fica evidenciado pelo fato de essa situação ter elevado o $\mathrm{pH}$, promovido aumento progressivo das concentrações de $\mathrm{P}$ e matéria orgânica, ocasionado redução linear de $\mathrm{Al}$ e contribuindo para a obtenção de maiores concentrações de $\mathrm{Ca}$ e Mg (Tabela 2), fatores que, segundo Malavolta et al. (1997), favorecem o crescimento das plantas. A concentração de P, por exemplo, com a adição crescente de coprólitos na composição do substrato, chegou, segundo Plank (1989), a uma condição mais próxima da ideal (8 a $\left.13 \mathrm{mg} \mathrm{L}^{-1}\right)$. De acordo com Taiz \& Zeiger (2004), o aumento no teor de fósforo estimula o crescimento radicular, principalmente na fase inicial de crescimento da planta, promovendo ampliação da área de absorção de água e nutrientes.

Embora a adição de doses crescentes de coprólitos ao solo tenha tornado a condição de fertilidade dos substratos cada vez mais adequada ao atendimento das necessidades nutricionais das plantas (Tabela 2), há de se considerar que, na medida em que se aumentou a concentração de coprólitos na composição do substrato, houve redução da porosidade total e do teor de argila e aumento das porcentagens de areia e silte (Tabela 4), situação que, segundo Fernandes et al. (2006), pode comprometer a qualidade físico-hídrica dos substratos. Entretanto, o aumento do crescimento das plantas, expresso pelo incremento em altura (Figura 1) e massa seca (Figura 2), obtido em decorrência do acréscimo gradativo de coprólitos na composição dos substratos, evidencia que a melhoria da condição química dos substratos, pelo aumento da concentração de coprólitos, superou qualquer possível efeito prejudicial ao crescimento das plantas relacionado à condição física dos substratos.

É importante destacar que, neste experimento, houve perda de parcelas dos tratamentos T1 ( $0 \%$ coprólitos e $100 \%$ solo); T2 (10\% coprólitos e $90 \%$ solo); T3 (20\% coprólitos e $80 \%$ solo), e T4 (30\% coprólitos e $70 \%$ solo) sendo 10 do T1, 8 do T2, 2 do T3 e 2 do T4. Em todos os casos, as plantas "morreram" antes da época de avaliação. Essa situação indica que a condição química deste solo era fortemente desfavorável ao atendimento das 
necessidades nutricionais das plantas e somente foi tornandose mais favorável, a partir da presença de doses crescentes de coprólitos na composição dos substratos.

No experimento 2, realizado com solo eutrófico, observouse diferença significativa entre os tratamentos apenas para a altura de planta (Figura 1) e para as massas de matéria seca da raiz e total (Figura 3). Entretanto, neste experimento, ao contrário do que ocorreu no anterior, verificou-se a redução de crescimento das plantas em resposta à adição de doses crescentes de coprólito na composição do substrato. Essa situação deve-se em grande parte ao fato de a condição química deste solo ser mais adequada que a dos coprólitos no atendimento das necessidades nutricionais das plantas. Portanto, na medida em que o solo foi sendo substituído pelos coprólitos, os substratos tornaram-se quimicamente cada vez mais desfavoráveis em promover o crescimento das plantas.

Neste experimento, ao contrário do que se verificou no anterior, a adição de doses crescentes de coprólitos ao solo não causou redução da porosidade total dos substratos nem tampouco alterou a concentração de areia, fatores relacionados com sua dinâmica hídrica (Fernandes \& Corá, 2000; Fernandes et al., 2006).

$\mathrm{O}$ pH do substrato é muito importante na produção de mudas, pois a maior parte dos nutrientes $(\mathrm{N}, \mathrm{P}, \mathrm{K}, \mathrm{Ca}, \mathrm{Mg}, \mathrm{S})$ estão menos disponíveis em baixos valores, podendo comprometer o crescimento das plantas (Malavolta et al., 1997). Para substratos minerais, valores entre 6,0 e 7,0 normalmente asseguram adequada disponibilidade de nutrientes. Entretanto, para substratos orgânicos, o ideal são valores em torno de 5,2 a 5,5 (Kämpf, 2000). Portanto, no caso do experimento 1 (solo distrófico), a adição de doses crescentes de coprólitos tornou o $\mathrm{pH}$ dos substratos mais próximo do ideal, passando a uma condição mais adequada em disponibilizar nutrientes para as plantas. Porém, no caso do experimento 2 (solo eutrófico), a adição de doses crescentes de coprólitos tornou o $\mathrm{pH}$ dos substratos mais distante do ideal, passando a uma condição mais inadequada em disponibilizar nutrientes para as plantas.

Analisando-se ambos os experimentos, verifica-se que a adição de doses crescentes de coprólitos ao solo provocou mudanças mais químicas do que físicas nos substratos. Essas mudanças foram, de forma geral, mais favoráveis ao crescimento das plantas quando o coprólito apresentou condição química mais adequada que o solo no atendimento das necessidades nutricionais das plantas. Embora a produção de mudas de mamão seja atualmente realizada normalmente em tubetes e com substratos com nível nutricional balanceado, os resultados do experimento com solo distrófico indicam a possibilidade de uso dos coprólitos na produção tradicional de mudas de mamoeiro em sacos plásticos, especialmente em situações onde o solo apresenta restrições quanto à condição química.

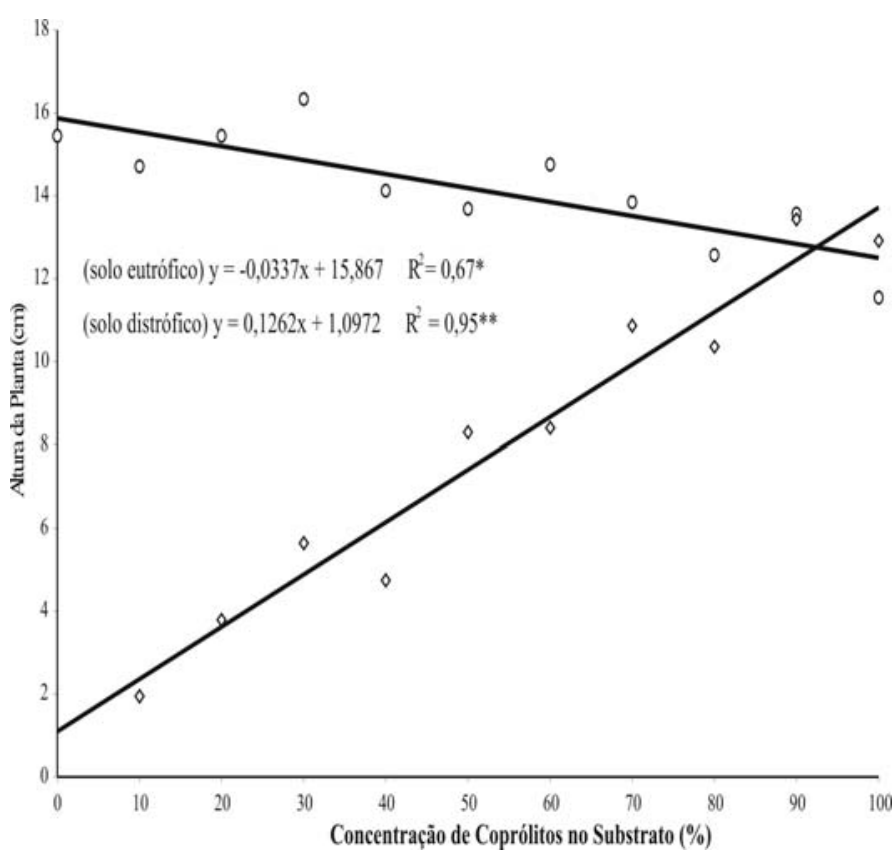

FIGURA 1 - Altura das plantas de mamão em função de substrato preparado à base de coprólitos de minhocas e solo distrófico $(\diamond)$ e solo eutrófico $(o)$.

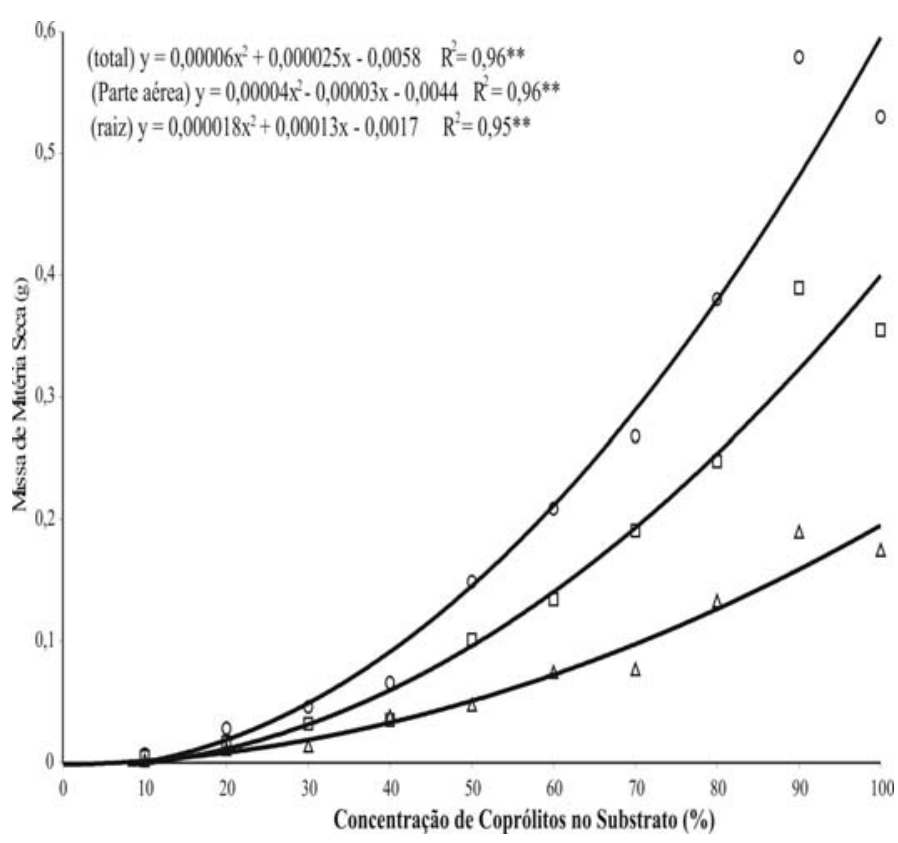

FIGURA 2 - Massa da matéria seca da raiz, parte aérea e total de mamoeiro formosa em função de substratos preparados com coprólitos de minhocas e solo distrófico. 


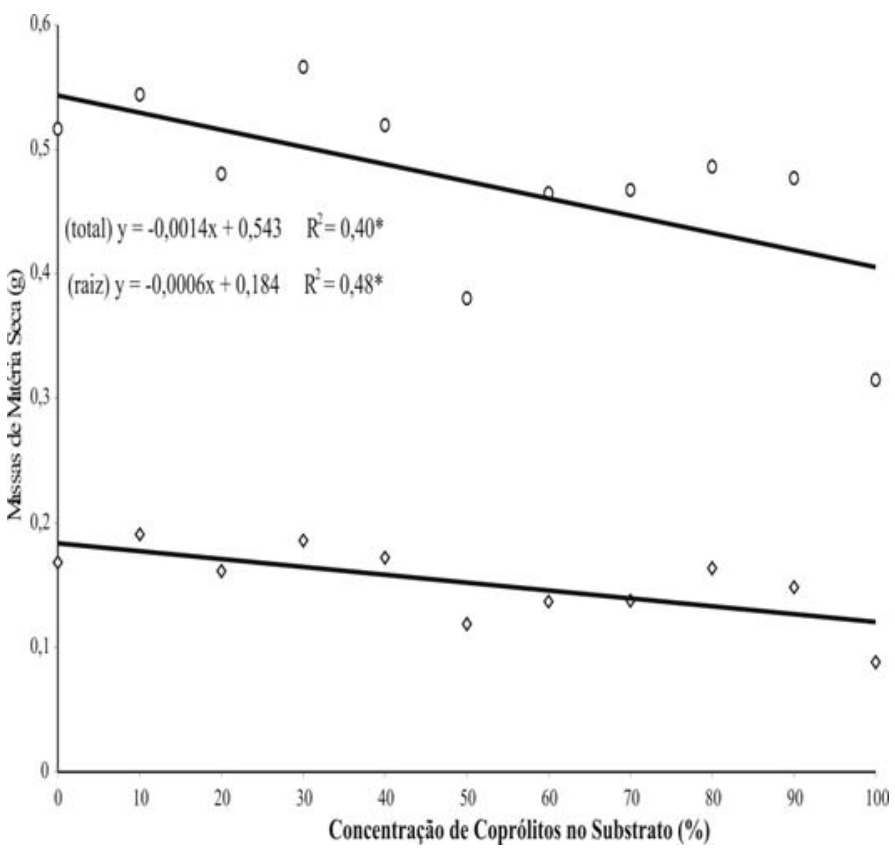

FIGURA 3 - Massa da matéria seca da raiz e total de mamoeiro formosa em função de substratos preparados com coprólitos de minhocas e solo eutrófico.

TABELA 1 - Concentrações de solo e coprólitos na composição dos substratos utilizados na produção de mudas de mamão formosa.

\begin{tabular}{|c|c|c|c|c|}
\hline \multirow{2}{*}{ Tratamentos } & \multicolumn{2}{|c|}{ Experimento 1} & \multicolumn{2}{|c|}{ Experimento 2} \\
\hline & Solo Distrófico & Coprólito & Solo Eutrófico & Coprólito \\
\hline $\mathrm{T} 1$ & $100 \%$ & $0 \%$ & $100 \%$ & $0 \%$ \\
\hline $\mathrm{T} 2$ & $90 \%$ & $10 \%$ & $90 \%$ & $10 \%$ \\
\hline T3 & $80 \%$ & $20 \%$ & $80 \%$ & $20 \%$ \\
\hline $\mathrm{T} 4$ & $70 \%$ & $30 \%$ & $70 \%$ & $30 \%$ \\
\hline T5 & $60 \%$ & $40 \%$ & $60 \%$ & $40 \%$ \\
\hline T6 & $50 \%$ & $50 \%$ & $50 \%$ & $50 \%$ \\
\hline $\mathrm{T} 7$ & $40 \%$ & $60 \%$ & $40 \%$ & $60 \%$ \\
\hline $\mathrm{T} 8$ & $30 \%$ & $70 \%$ & $30 \%$ & $70 \%$ \\
\hline T9 & $20 \%$ & $80 \%$ & $20 \%$ & $80 \%$ \\
\hline T10 & $10 \%$ & $90 \%$ & $10 \%$ & $90 \%$ \\
\hline $\mathrm{T} 11$ & $0 \%$ & $100 \%$ & $0 \%$ & $100 \%$ \\
\hline
\end{tabular}

TABELA 2 - Composição química dos substratos com diferentes concentrações de coprólitos de minhoca em solo distrófico.

\begin{tabular}{|c|c|c|c|c|c|c|c|c|c|c|c|c|}
\hline \multirow{2}{*}{ Tratamentos } & $\mathrm{pH}$ & $\mathrm{Na}$ & $\mathrm{K}$ & $\mathrm{Ca}$ & $\mathrm{Mg}$ & $\mathrm{A} 1$ & $\mathrm{H}+\mathrm{Al}$ & SB & $T$ & $\mathrm{~V}$ & $\mathrm{MO}$ & P-rem \\
\hline & $\left(\mathrm{H}_{2} \mathrm{O}\right)$ & \multicolumn{8}{|c|}{$\mathrm{cmol}_{\mathrm{c}} \mathrm{dm}^{-3}$} & $(\%)$ & dag. $\mathrm{kg}^{-1}$ & mg.L $\mathrm{L}^{-1}$ \\
\hline T1 & 4,0 & 0,04 & 0,13 & 0,30 & 0,70 & 1,75 & 2,91 & 1,17 & 4,08 & 28,68 & 1,66 & $<1$ \\
\hline $\mathrm{T} 2$ & 4,0 & 0,04 & 0,15 & 0,60 & 0,80 & 1,70 & 3,38 & 1,59 & 4,97 & 31,99 & 4,07 & 1 \\
\hline T3 & 4,0 & 0,04 & 0,13 & 1,00 & 1,00 & 1,65 & 3,99 & 2,17 & 6,16 & 35,23 & 6,01 & 2 \\
\hline $\mathrm{T} 4$ & 4,0 & 0,04 & 0,13 & 1,25 & 1,00 & 1,40 & 4,23 & 2,57 & 6,80 & 37,79 & 11,23 & 5 \\
\hline T5 & 4,0 & 0,04 & 0,13 & 1,40 & 1,00 & 1,40 & 4,51 & 2,57 & 7,08 & 36,30 & 11,56 & 5 \\
\hline T6 & 4,0 & 0,04 & 0,16 & 1,35 & 0,95 & 1,20 & 5,07 & 2,50 & 7,57 & 33,03 & 13,69 & 7 \\
\hline $\mathrm{T} 7$ & 4,1 & 0,04 & 0,11 & 1,50 & 1,40 & 1,15 & 5,26 & 3,05 & 8,31 & 36,70 & 14,89 & 9 \\
\hline T8 & 4,1 & 0,04 & 0,11 & 1,65 & 1,40 & 1,00 & 5,10 & 3,20 & 8,30 & 38,55 & 15,72 & 12 \\
\hline T9 & 4,2 & 0,04 & 0,11 & 1,60 & 1,40 & 1,00 & 4,32 & 3,15 & 7,47 & 42,17 & 16,83 & 15 \\
\hline T10 & 4,2 & 0,04 & 0,11 & 1,50 & 1,30 & 0,80 & 4,98 & 2,95 & 7,93 & 37,20 & 17,39 & 17 \\
\hline T11 & 4,4 & 0,04 & 0,13 & 2,45 & 1,65 & 0,60 & 4,70 & 4,27 & 8,97 & 47,60 & 19,29 & 18 \\
\hline
\end{tabular}

TABELA 3 - Composição química dos substratos com diferentes concentrações de coprólitos de minhoca em solo eutrófico.

\begin{tabular}{|c|c|c|c|c|c|c|c|c|c|c|c|c|}
\hline \multirow{2}{*}{ Tratamentos } & $\mathrm{pH}$ & $\mathrm{Na}$ & $\mathrm{K}$ & $\mathrm{Ca}$ & $\mathrm{Mg}$ & $\mathrm{A} 1$ & $\mathrm{H}+\mathrm{Al}$ & SB & $\mathrm{T}$ & $\mathrm{V}$ & MO & P-rem \\
\hline & $\left(\mathrm{H}_{2} \mathrm{O}\right)$ & \multicolumn{8}{|c|}{$\mathrm{cmol}_{\mathrm{c}} \mathrm{dm}^{-3}$} & $(\%)$ & dag.kg ${ }^{-1}$ & $\overline{\text { mg.L }}$ \\
\hline T1 & 5,0 & 0,04 & 0,21 & 5,50 & 1,60 & 0,25 & 1,88 & 7,35 & 9,23 & 79,63 & 9,99 & 17 \\
\hline T2 & 4,8 & 0,08 & 0,19 & 5,15 & 1,80 & 0,15 & 2,67 & 7,22 & 9,89 & 73,00 & 11,77 & 29 \\
\hline T3 & 4,7 & 0,08 & 0,19 & 4,95 & 1,45 & 0,15 & 2,82 & 6,67 & 9,49 & 70,28 & 12,95 & 20 \\
\hline $\mathrm{T} 4$ & 4,7 & 0,08 & 0,17 & 4,25 & 1,85 & 0,10 & 3,05 & 6,35 & 9,40 & 67,55 & 13,87 & 15 \\
\hline T5 & 4,7 & 0,08 & 0,18 & 4,25 & 1,75 & 0,25 & 3,43 & 6,26 & 9,69 & 64,60 & 15,44 & 20 \\
\hline T6 & 4,6 & 0,08 & 0,17 & 4,00 & 1,70 & 0,30 & 3,66 & 5,95 & 9,61 & 61,91 & 17,57 & 20 \\
\hline $\mathrm{T} 7$ & 4,6 & 0,08 & 0,18 & 3,50 & 2,00 & 0,35 & 4,13 & 5,76 & 9,89 & 58,24 & 16,83 & 19 \\
\hline T8 & 4,6 & 0,04 & 0,16 & 3,40 & 1,75 & 0,35 & 3,99 & 5,35 & 9,34 & 57,28 & 18,03 & 19 \\
\hline T9 & 4,5 & 0,04 & 0,17 & 3,25 & 1,60 & 0,35 & 3,99 & 5,06 & 9,05 & 55,91 & 23,74 & 17 \\
\hline T10 & 4,4 & 0,04 & 0,13 & 2,50 & 1,55 & 0,45 & 4,32 & 4,22 & 8,54 & 49,41 & 21,51 & 18 \\
\hline T11 & 4,4 & 0,04 & 0,13 & 2,45 & 1,65 & 0,60 & 4,70 & 4,27 & 8,97 & 47,60 & 19,29 & 18 \\
\hline
\end{tabular}


TABELA 4 - Características físicas dos substratos considerados como tratamentos dos experimentos 1 e 2.

\begin{tabular}{|c|c|c|c|c|c|c|c|c|c|c|c|c|}
\hline \multirow{3}{*}{ Tratamentos } & \multicolumn{6}{|c|}{ Experimento 1 - Solo Distrófico } & \multicolumn{6}{|c|}{ Experimento 2 - Solo Eutrófico } \\
\hline & Da & Dp & $\mathrm{Pt}$ & Areia & Silte & Argila & $\mathrm{Da}$ & $\mathrm{Dp}$ & $\mathrm{Pt}$ & Areia & Silte & Argila \\
\hline & \multicolumn{2}{|c|}{ g.dm ${ }^{-3}$} & \multicolumn{4}{|c|}{$(\%)$} & \multicolumn{2}{|c|}{ g.dm } & \multicolumn{4}{|c|}{$(\%)$} \\
\hline T1 & 1,04 & 2,63 & 60 & 29 & 22 & 49 & 1,33 & 2,67 & 50 & 47 & 31 & 22 \\
\hline $\mathrm{T} 2$ & 1,07 & 2,60 & 59 & 29 & 26 & 45 & 1,25 & 2,53 & 50 & 49 & 30 & 21 \\
\hline T3 & 1,09 & 2,60 & 58 & 33 & 26 & 41 & 1,24 & 2,50 & 50 & 51 & 31 & 18 \\
\hline T4 & 1,09 & 2,60 & 58 & 34 & 31 & 35 & 1,22 & 2,50 & 51 & 49 & 33 & 18 \\
\hline T5 & 1,11 & 2,60 & 57 & 35 & 32 & 33 & 1,20 & 2,50 & 52 & 51 & 32 & 17 \\
\hline T6 & 1,10 & 2,56 & 57 & 39 & 34 & 27 & 1,18 & 2,47 & 52 & 50 & 32 & 18 \\
\hline T7 & 1,10 & 2,50 & 56 & 42 & 33 & 25 & 1,16 & 2,47 & 53 & 48 & 36 & 16 \\
\hline T8 & 1,12 & 2,47 & 55 & 41 & 36 & 23 & 1,15 & 2,44 & 53 & 50 & 35 & 15 \\
\hline T9 & 1,13 & 2,44 & 54 & 43 & 39 & 18 & 1,13 & 2,44 & 54 & 47 & 41 & 12 \\
\hline T10 & 1,17 & 2,41 & 51 & 49 & 37 & 14 & 1,14 & 2,41 & 53 & 52 & 36 & 12 \\
\hline $\mathrm{T} 11$ & 1,17 & 2,38 & 51 & 49 & 41 & 10 & 1,17 & 2,38 & 51 & 49 & 41 & 10 \\
\hline
\end{tabular}

\section{CONCLUSÕES}

1- O uso de substratos preparados com solo e coprólitos de minhoca somente contribui para o crescimento de mudas de mamão formosa se a condição química dos coprólitos for mais adequada que a do solo em atender às necessidades nutricionais das plantas.

2- Há potencial de uso de coprólitos de minhoca na composição de substratos para produção tradicional de mudas de mamão formosa, quando se utiliza apenas solo e este apresenta restrições quanto à condição química necessária ao atendimento adequado das necessidades nutricionais das plantas.

\section{REFERÊNCIAS}

AGRIANUAL 2006: anuário estatístico da agricultura brasileira. São Paulo: FNP Consultoria e Comércio, 2005. 521 p.

BAKKER, A. P. de. Efeito do húmus de minhoca e da inoculação do fungo micorrízico arbuscular (Glomus macrocarpum) sobre o desenvolvimento de mudas de porta-enxertos de cajueiro anão precoce (Anaccardium occidentale L.). 1994. 61 f. Dissertação (Mestrado em Solos e Nutrição de Plantas) - Universidade Federal do Ceará, Fortaleza, 1994.

BLANK, A. F.; ARRIGONI-BLANK, M. F.; SILVA, P.A.; TORRES, M. E.; Menezes, H. J. A. Efeitos de composições de substratos na produção de mudas de quiôiô (Ocimum gratissimum L.). Revista Ciência Agronômica, Fortaleza, v. 34, n.1, p. 5-8, 2003.

CABRERA, R. A. D. Produção de mudas cítricas em viveiro: uso de substrato alternativo e inoculação com Xylella fastidiosa. 2004. 122 f. Dissertação (Mestrado em Ecologia de Agroecossistemas) - Escola Superior de Agricultura Luiz de Queiroz, Piracicaba, 2004.

CASTRO, C.M.; RIBEIRO, R. L. D.;ALMEIDA, D. L. Caracterização e avaliação de substratos orgânicos para produção de mudas de beterraba. Agronomia, Seropédica, v. 37, n. 2, p.19-24, 2003.

DINIZ, K. A.; LUZ, J. M. Q.; MARTINS, S. T.; DUARTE, L. C. Produção de mudas de tomate e pimentão em substrato a base de vermicomposto. Horticultura Brasileira, Brasília, v.19, jul. 2001. Suplemento.

FACHINELlO, J. C.; HOFFMANN, A.; NACHTIGAL, J. C. Propagação de plantas frutíferas. Brasília: Embrapa Informação Tecnológica, 2005.221 p.

FERNANDES, C.; CORÁ, J. E. Caracterização físico-hídrica de substratos utilizados no cultivo de hortaliças. Horticultura Brasileira, Brasília, v. 18, p. 471-473, jul. 2000. Suplemento.

FERNANDES, C.; CORÁ, J. E.; BRAZ, L. Desempenho de substratos no cultivo do tomateiro do grupo cereja. Horticultura Brasileira, Brasília, v. 24, n.1, p. 42-46, jan.-mar. 2006.

GUERRA, R. T. Ecologia dos Oligochaeta da Amazônia. II. Estudo da estivação e da atividade de Chibui bari (Glossoscolecidae, Oligochaeta) através da produção de excrementos. Acta Amazônica, Manaus, v.18, n. 2, p. 27-34, 1988.

KÄMPF, A. N. Seleção de materiais para uso como substrato. In: KÄMPF, A.N.; FERMINO, M.H. (Ed.). Substrato para plantas: a base da produção vegetal em recipientes. Porto Alegre: Gênesis, 2000. p. 139-145.

MALAVOLTA, E.; VITTI, G. C.; OLIVEIRA, S. A. de. Avaliação do estado nutricional das plantas: princípios e aplicações. 2. ed. Piracicaba: Potafós, 1997.319 p.

MARTINS, S. T.; LUZ, J. M. Q.; DINIZ, K. A. Produção de mudas de alface em substrato a base de vermicomposto. Horticultura Brasileira, Brasília, v. 19, jul. 2001. Suplemento. CD-ROM.

MENDONÇA, V.; ARAÚJO NETO, S. E. de; RAMOS, J. D.; PIO, R.; GONTIJO, T. C. A. Diferentes substratos e recipientes na formação de mudas de mamoeiro 'Sunrise solo'. Revista Brasileira de Fruticultura, Jaboticabal, v. 25, n. 1, p. 127-130, abr. 2003.

MENEZES JÚNIOR, F. O. G.; FERNANDES, H. S. Substratos formulados com vermicomposto e comerciais na produção de mudas de couve-flor. Revista Brasileira de Agrociência, Pelotas, v. 4, n. 3, p. 191-196, set.-dez. 1998. 
PLANK, C. O. Soil test handbook for Georgia. Athens: University of Georgia, 1989.316 p.

RAMOS, J. D.; CHALFUN, N. N. J.; PASQUAL, M.; RUFINI, J. C. M. Produção de mudas de plantas frutíferas por semente. Informe Agropecuário, Belo Horizonte, v. 23, p. 64-72, 2002.

SILVEIRA, E. B.; RODRIGUES, V. J. B.; GOMES, A. M. A.; MARIANO, R. L. R.; MESQUITA, J. C. P. Pó de coco como substrato para produção de mudas de tomateiro. Horticultura Brasileira, Brasília, v. 20, n. 2, p. 211-216, jun. 2002.

SOUZA, C. A. S.; CORRÊA, F. L. de O.; MENDONÇA, V.; CARVALHO, J. G. de. Crescimento de mudas de gravioleira (Anonna muricata L.) em substrato com superfosfato simples e vermicomposto. Revista Brasileira de Fruticultura, Jaboticabal, v. 25, n.3, p. $453-456$, dez. 2003.
SOUZA, J. L. de; RESENDE, P. Manual de horticultura orgânica. Viçosa: Aprenda Fácil, 2003. 546 p.

TAIZ, L.; ZEIGER, E. Fisiologia vegetal. 3. ed. Porto Alegre: Artmed, 2004.719p.

VIDAL, L. H. I. ; SOUZA, J. R. P. ; FONSECA, E. P.; BORDIN, I. Qualidade de mudas de guaco produzidas por estaquia em casca de arroz carbonizada com vermicomposto. Horticultura Brasileira, Brasília, v. 24, n. 1, p. 26-30, 2006. 